\title{
ON THE RELATION BETWEEN PRESSURE AND EVAPORATION
}

BY EDWIN H. HAII

Many years ago Thomson showed that the maximum vapor pressure in contact with the concave surface of a liquid, elevated by capillary action, nunst be less than the maximum pressure over a flat surface of the liquid at the same temperature. Maxwell's reference to this matter leaves it to be supposed that the diminution of rapor-pressure is due directly to the curvature of the surface in the tube.

But, according to riews set forth by Poynting, ${ }^{2}$ the maximum pressure of a rapor in contact with its liquid at a given temperature is dependent upon the total pressure to which the liquid is subjected; and Poynting attributes the smallness of the pressure above a concare surface to the small pressure borne by the liquid just bencath the surface. Howerer sonnd Poynting's theory, his statement of it at this point lacks clearness; for the fact is apt to stick in the mind of the reader that evaporation and condensation occur, if at all, at the curved surface, and that this surface is subjected to the full pressure of the atmosphere; so that the pertinence of referring the state of the vapor to the state of the liquid beneath the surface is not obrious.

Le Blanc, ${ }^{3}$ although he does not mention Poynting, maintains an opinion similar to that expressed by the latter, and gives conclusive arguments in faror of it. He refers to an article by Schiller ${ }^{+}$on the same subject.

\footnotetext{
'See Maswell's Heat.

2Phil. Mag., July, I88 I, ant Octoher, г896.

${ }^{3}$ Electro-Chemistry, I5I, English edition.

4 Wied. Ann. 53, 396 (1894).
} 
The special algebraic expression obtained below for the relation between temperature, vapor-density, and total pressure, may have been given before, although I do not remember to have seen it; but in any case I hope that the method of its derivation, by following up a commonly neglected term in a familiar operation, will possess a certain interest.

Nernst, Theoretische Chomie, p. 510 of the first German edition, derives the "equation of the reaction-isotherms,"

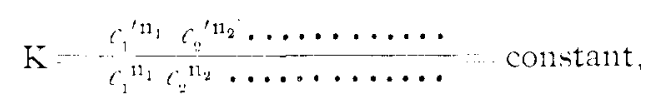

in the following manner: Starting with a mixture in which the reaction occurs according to the scheme,

$v_{1} a_{1} \cdots v_{2} a_{2}-\ldots-n_{1} A_{1}-n_{2} A_{2}-\cdots=-?$

$$
v_{1}^{\prime} a_{1}^{\prime}-v_{2}^{\prime} a_{2}^{\prime} \ldots \ldots n_{1}^{\prime} A_{1}^{\prime} \quad n A_{2}^{\prime} \cdots \cdots
$$

where every $a$ refers to a solid or to a liquid which does not nix with the other substances present and every $A$ to a gaseous or dissolved constituent, every $r$ to the number of gm. 111ol. of its a entering into the reaction and every $n$ to the number of gin. mol. of its A entering into the reaction, the whole being contained in a ressel of unchanging volume, Nernst imagines the reaction to go on from left to right with no change whatever in the condition of the reaction mixture, the left-hand constituents being forced in as fast as they are consumed by the reaction and the right-hand constitnents forced ont as fast as they are produced. The whole operation, being carried on reversibly and isothermally, gives the same annonnt of work which would be given by any other reversible isothermal process proceeding from the same initial to the same final conditions. Nernst writes this amount of work thus,

$$
\text { F } \quad \operatorname{RT}\left(n_{1} l n c_{1}-n_{2} l c_{2} \ldots \ldots-n_{1}^{\prime} l n c^{\prime} \ldots n_{2}^{\prime} n_{2}^{\prime} \ldots \ldots\right) \text {. }
$$

whence

$$
\mathrm{F}=\mathrm{R} \mathrm{T} / n \frac{c_{1}^{\prime n_{1}} c_{2}^{\prime n_{2}} \ldots \ldots \ldots}{c_{1}^{\mathrm{n}_{1} c_{2} \mathrm{n}_{2}} \ldots \ldots \ldots \ldots} \quad \mathrm{R} \mathrm{T} / n \mathrm{~K}
$$

where each $c$ is the concentration of the corresponding $A$ in the 
mixture. Then, as F, however the individual is may rary, is a constant, $K$ must be a constant; which was the proposition to be proved.

A close examination of the conditions given by Nernst shows, howerer, that the value of $F$ above given is not, in greneral, true. The $\mathrm{f} u 11$ expression for $F$ is

where

$$
\mathrm{F}, \mathrm{RT} \ln \mathrm{K} \quad \mathrm{RT} \mathrm{N}-\mathrm{N}, \ldots \mathrm{PI} \quad \mathrm{N}^{\prime}
$$

$$
\begin{aligned}
& \begin{array}{cccc}
\mathrm{N} & n_{1} & n_{0} & \ldots \\
\mathrm{N} & n_{1} & n_{2} & \cdots
\end{array} \\
& \checkmark \text { volume of } v_{1} a_{1}, v_{2} a_{2}, \ldots
\end{aligned}
$$

P total pressure per unit surface within the reaction mixture.

In this amended equation, (2), the terms $\mathrm{F}$ and $\mathrm{RT}\left(\mathrm{N}-\mathrm{N}^{\prime}\right.$ ) being constant at constant $T$, the only impeachment of the conclusion that $\mathrm{R} T / n \mathrm{~K}$, and so $\mathrm{K}$, is a constant, lies in the variation of the term $P\left(V^{\prime}-V^{\prime \prime}\right)$ with change of $P$. This change, though usually small, since the whole term $\mathrm{P}\left(\mathrm{V} \times \mathrm{V}^{\prime}\right)$ is likely to be small, is unquestionable, and we must conclude that $\mathrm{K}$, as defined by Nernst with reference to the 's only, is not strictly a

"The initial condition of the A constituents ontsirle the reaction vessel. and the funal conclition of the A' constituents ontirfe the reaction ressel. is unit concentration, in gas or solution. The reversible, isothermal introduction of $n_{1}$ gm. mol. of $A_{1}$, for example. into the reaction-vensel involycs, first, isothermal expansion fron density $I$ to density $c_{1}$, vielding $\ldots n_{1} \mathrm{RT} / m_{1}$ units of work ; second. injection at constant density $c_{1}$, thronsh a semipermeable partition, absorbing $n_{1} \mathrm{R} T$ units of work. The net amount of work obtained from this operation is $n \mathrm{R}^{\mathrm{T}}$ /nc is similarly, the net amount of work obtained by the ejection of $n_{1}^{\prime}$ gnn. mol. of $A_{1}^{\prime}$ at constant density $q_{1}^{\prime}$, and its subsequent

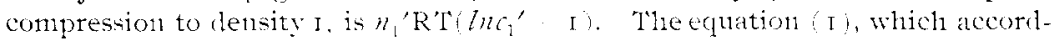
ing to Nernst shows the anount of work accomplished in the whole operation. ignores the fact that $\Sigma n$, or $X$, is not necestarily equal to $\Sigma n^{\prime}$, or $X^{\prime}$. Wre are. however, not concented with this inaccuracy, which is, by the way, elininated in Nernst's rerivation of the equation for the "reaction-isochor." The term $\mathrm{P}(\mathrm{Y}) \mathrm{V}$. which appears in 2 ?, obvionsly gives the net amonnt of external work obtained from the injection and ejection of the solicts or non-miscible liculids which take part in the operation. This anount of work is expressly. put asicle by Nernst as " maturtich grleich . Yull;" but it is the especial point of the present discussion. 
constant at constant 'T. I.et ns, therefore, take as the real equilibrinu constant

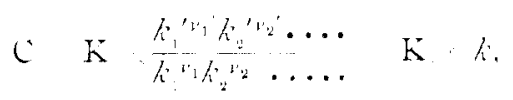

where $h_{i}$ bears the same relation to $a_{\text {, that }} c_{\text {, bears }}$ to $A_{i}$, etc.

Suldstituting now for $\mathrm{K}$ in (2), we get

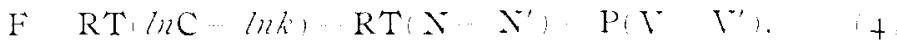

At constant temperature the only variable terms in this equation are $\mathrm{RT} / n k$ and $\mathrm{P}\left(\mathrm{V}^{*}\right.$..... $\left.\mathrm{V}^{\prime \prime}\right)$. Hence at constant temperature

$$
\mathrm{RThk} \mathrm{P} / \mathrm{V} \cdot \mathrm{V}, \mathrm{B},
$$

where $\mathrm{B}$ is a constant as regards $P$.

From (5) we get

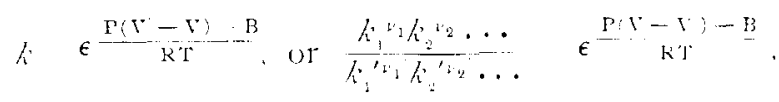

Where $\epsilon$ is the Napierian base.

Let us apply equation (6) to the case of a single liquid or solid in the presence of a gaseous phase consisting of the saturated vapor of this liquid or solid together with any number of other gases nentral to the first substance, the condensed plase of this substance being forced into an inclosure as fast, by weight, as its rapor is withdrawn, the "reaction" being simply evaporation. In this case $V^{\prime \prime}-0, v_{1} \cdots I$, and, if $a_{\tau}^{\prime}$ is the rolume of I w111. mol. of the substance in the conclensed plase, we get from (6)

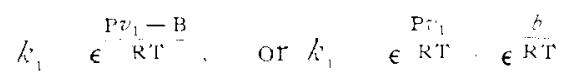

where $b=-B$.

It will be remembered that $B$, and so b. is independent of P. Hence the last equation may be written

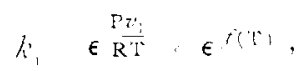

f ( T) being some function of $\mathrm{T}$.

Taking. for exanple, ice at $-10^{\circ} \mathrm{C}$ as the condensed phase. 
and reckoning in atmospheres and liters, we get for the vapordensity of water orer the ice

$$
N_{1}=\epsilon \frac{\mathrm{P}}{\mathrm{II00}} \times \epsilon^{f(\mathrm{~T})}
$$

when $\mathrm{P}$ is rery small, $\epsilon \frac{\mathrm{P}}{\mathrm{r} \text { roo }}$.... approximately $\mathrm{I}$

$$
\begin{aligned}
& \text {. . }
\end{aligned}
$$

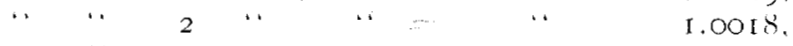

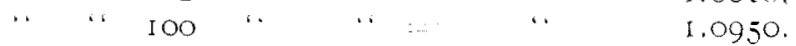

In the presence of liquid water at $0^{\circ} \mathrm{C}$, we should have $k_{\mathrm{r}}=\epsilon^{-\frac{\mathrm{P}}{1240}} \times \epsilon^{f(T)}$, where $f(\mathrm{~T})$ is not the same as in equation

(9). In this case

when $P$ is rery small $\epsilon_{\frac{1240}{10}}^{P}$ approximately I

$$
\begin{aligned}
& \text { " " } 1 \text { atmos, " } \quad \text { r. }
\end{aligned}
$$

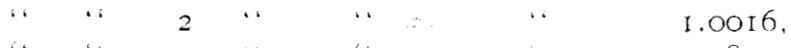

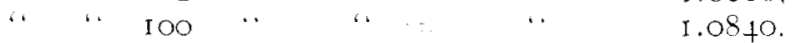

Of course, the same results can be found without any reference to the general "equation of the reaction-isotherm."

Cambridge, June I, rigg. 